\title{
ECT: TNT or TLC? A Near-Death Experience Triggered by Electroconvulsive Therapy
}

\author{
Keith Floyd, C. Psych., Ed.D. \\ Alberta Hospital Ponoka Psychiatric Treatment Centre
}

ABSTRACT: I report an experience in the course of electroconvulsive therapy (ECT) that was indistinguishable from an NDE. Aspects of the experience that had been terrifying for the individual were counterbalanced by her immediate and complete recovery from a suicidal depression. Beyond the transpersonal aspects of her NDE-like experience, the ECT triggered a precognitive vision that materialized two years later.

Now, my own suspicion is that the universe is not only queerer than we suppose, but queerer than we can suppose .. . I suspect that there are more things in heaven and earth than are dreamed of, or can be dreamed of, in any philosophy. That is the reason why I have no philosophy myself, and must be my excuse for dreaming.

J. B. S. Haldane, Possible Worlds (1927)

\section{Prelude}

This intriguing story first came to light following a psychology class that had come to life with a question about near-death experiences (NDEs). One student, a woman in her mid-30s, lingered after the others had left. What I had said about NDEs, she said, was so much like what happened to her that she felt she had to tell me about it. She stressed that she had never before shared the experience with anyone because she knew they would just think she was crazy.

Keith Floyd, C. Psych., Ed.D., practices psychology at the Alberta Hospital Ponoka Psychiatric Treatment Centre in Ponoka, Alberta. Reprint requests should be addressed to Dr. Floyd at the Alberta Hospital Ponoka, Psychology Department, P.O. Box 1000, Ponoka, Alberta, Canada T4J 1R8. 
Four years earlier, she went on, she had had a nervous breakdown and was in a deep suicidal depression. Her physician, despite her protests and pleadings, had arranged to have her committed to a nearby mental hospital (not the psychiatric treatment center where currently I practice psychology). The hospital's admitting psychiatrist prescribed electroconvulsive therapy (ECT), insisted it was the intervention of choice, and booked her for a series of treatments.

Having heard horror stories of "fried brains" and memory bankruptcy, and with visions of hollow-eyed zombies dancing in her head, she begged her doctor not to put her through what she had always thought of as her worst nightmare. He did his best to reassure her that ECT really wasn't all that bad and could be counted on to relieve her depression. She might have a bit of a headache for a few hours, he said, but they could give her something for that.

On the morning of her first and, as it turned out, only treatment, the nurse who arrived to "prep" her with premedication was assailed with further protestations and pleadings. The nurse did her best to comfort and reassure her while injecting the drug. Within seconds, the "twilight sleep" had set in and the patient found herself floating limply -in a sea of panic. Though she was sure she had appeared relaxed and calm on the surface, as she put it, "all hell was breaking loose underneath." Anger, she said, had been her only defense against overwhelming anxiety.

The anesthetic she saw as having revoked her will as it robbed her of all control of her voluntary muscles. Immobilized, her anguish dissolved into a buzzing silence of fear and quiet desperation. Paralyzed though she was by the medication, her awareness of everything going on around her was undiminished. Not only did she remain wide awake and fully conscious, she was "hyperaware," but could not so much as lift a finger or an eyelid to prove it to anyone. She described the feeling as "worse than a nightmare, like being raped."

A second nurse arrived to assist in lifting her onto a stretcher for the short trip to the treatment room. She struggled within to scream at them to stop, but found it impossible to move a muscle or make a sound. Fear turned to terror as they wheeled her down the corridor. She was intently aware of every word spoken along the way, of clicks of the wheels over joints in the floor, of the subtlest of smells, and of shifting shades of light and shadow playing on her closed eyelids. But it was the metallic taste of her own fear that she recalled most vividly. The apparent disregard of her plight by all concerned compounded the anxiety. 
The psychiatrist and his assistant were awaiting her arrival in the ECT room with their equipment warm and humming, and it was with pained amusement that she recalled being wheeled in and overhearing the two talking about golf. The doctor lifted her flaccid arm and let it drop, noting to his colleague that she was almost ready. As she fought vainly to cry out that she was not ready, he raised one of her eyelids and beamed a penlight into her pupil as he proceeded with his routine.

Glaring past the light directly into his pupil, she strained to communicate wordlessly through sheer force of rage that she had had enough and wanted out of there, but was unable to move or make a sound. As her eyelid was released, the shutter of her mind snapped, and the darkness closed in on her. It was then she knew there was no hope of rescue or escape. Bracing herself as best she could with thoughts of loved ones who still cared, desperately she tried to prepare herself mentally for the worst. No prisoner about to die in the electric chair, she told me, had ever been more terrified.

The electroconductive paste was applied and the clamp with its harness of wires was set to press tightly against her temples. With the requisite injection of the muscle relaxant, a tidal wave of panic swept through her, driven by the cessation of her breathing, and she was left without a shred of doubt that she was about to die-or worse. Her sense of helplessness, she said, was absolute, and to abandon hope and welcome death seemed her only way out.

She felt doubly enraged, she said, that her caregivers were making her predicament all the more terrifying by going through the motions of a mechanical routine: straps cinched, patient secured; mouthpiece clenched, airway assured; ground-patch attached; foam grips in fists; switch tripped; end checklist.

In a split second, the juice hit. Billions upon billion of neurons ignited simultaneouly, and a thousand suns exploded inside her head. For a few excruciating seconds, the conflagration raged as the electric current flashed across her brain lobes, and in that timeless moment of ego immolation, she had been, as she put it, "to hell and back." The pain, she testified, was unimaginable, but thankfully was over almost before it began, having burned itself out in the electrical storm that triggered her convulsions-though it might have lasted for eternity, for all she knew at the time.

She had no recollection of the seizure itself, or of the moment the oxygen mask was placed over her mouth and nose, but she said she would never forget the moment of grace when the saving gas flooded 
her lungs and washed the blues-of her skin-away. And the brainstorm that followed the lightning flash, she was soon to discover, had blown away years of accumulated clutter from the furrows of her mind.

\section{The Near-Death Experience}

No sooner had the pain disappeared than, trite as it may sound, she found herself rushing down a long, spiraling tunnel toward what she described as an overwhelmingly brilliant, dazzling pinpoint of light. The ambivalence she felt in approaching the light was fraught with desire and dread so deep and so high she saw it as being "of cosmic significance." The holding back and letting go were pitted against each other in an archetypal struggle, a harbinger of Armageddon, with all the agony and ecstasy of heaven and hell. The desire to let go and go into the light and her agonizing dread in resisting were one and the same. She knew it sounded insane, she said, but anxiety and ecstasy were exactly the same, "not opposites at all-just mirror images of each other."

Suddenly the rush of shooting down the tube toward the light was interrupted, the tension broken, by the intrusion of a lifelike scene, as if on a cinema screen enclosed within the tunnel and appearing as a barrier between herself and the light. She described it as "a sort of gossamer T.V. screen" that momentarily blocked her passage with a vivid, sharply focused, full-color, fluid-motion, three-dimensional scene from her childhood. Instantly, she recognized it as an exact "re-creation," an instant replay, of her fifth birthday party, with every detail intact, precisely as if she were viewing a movie of the original event, but with all the subtantiality and sensations of virtual reality. "It wasn't just remembering the way it was back then," she insisted, "I was there!"

The scene, at first, was observed from a distance. As she moved closer, continuing down the tunnel, she perceived the images coming fully into focus as she merged with the scene, was five years old all over again and, once more, was thoroughly enjoying the celebration.

Although she said she could never have remembered highly specific particulars of names and games, laughter and talk, treats and gifts, it remained perfectly clear to her four years later that her reprise of the event in the tunnel was precisely the way everything had hap- 
pened in the backyard of her family home 30 years before, accurate down to the most minute detail.

Having "relived" the entire party in what she guessed to have been no more than 10 to 15 seconds, real time, she passed on through the scene, was again rushing headlong down the tunnel unhindered by distractions, and it felt to her as if terminal velocity of that "rush" might have been near the speed of light.

Presently, another moving picture from her past zoomed into focus on that incorporeal screen obstructing her passage on her way to the light. This time, she was at her high school graduation ceremony, with all her classmates in their caps and gowns and the teachers and parents looking very pleased and proud. Again, she insisted it was not mere abstract remembering, but a concrete reliving of the original event, exactly as she had experienced it some 17 years earlier. She stressed that it was as different from ordinary memory and visual imagery as reading a menu is different from eating a meal. At the very least, it was clear evidence of a photographic memory she had never known she possessed, or it might have passed for the most lucid of dreams. Still, the feeling persisted years later that she had experienced a literal revisit to the past, a "rematerialization" of the actual event.

As the second of her reconstituted "rites of passage" faded back into the past and rapidly receded behind her in the tunnel, her speed increased as she was drawn toward the light "like a speck of dust in a vacuum hose."

Other scenes from her past were described in less elaborate detail, but she insisted they were no less complete. As was so for the birthday party and graduation ceremony, each definitive image within the multiplicity of scenes was perceived as having arisen from, and coalesced in, patterns of dark/light ambiguity superimposed on her bedazzled perception of the light at the end of the tunnel.

Likewise, there was every appearance that the lifelike movement of images within scenes was created in the interplay of shifting figure/ground relationships within patterns that had originated in ambiguity and culminated in lucidity. And each scene that had intervened to that point, she said, corresponded in every particular to crystal clear memories of events that had taken place earlier in her life.

She had come to view the phenomenon with great fascination and a natural assumption that the intruding scenes intermittently disrupting her progression toward the light evidently-necessar- 
ily-were derived from personal memories of past experiences. But that "illusion," she said, was shattered by the startling materialization of an event unlinked to her past, and having no discernible connections in conscious awareness.

As she drew closer and blended into that baffling apparition, suddently she was at a cocktail party, "as real in every respect as any party I have ever attended." Describing the scene in intricate detail, she recounted how she was escorted into an elegantly-appointed living room in a spacious, unfamiliar home, was introduced to a small group of guests and was welcomed by a sophisticated-looking woman in a black, satin dress, holding a cigarette in one hand a highball glass in the other. Next to her was a man wearing a houndstooth sports jacket, sipping a martini. Others in the circle were described in similar detail, and she recounted verbatim the conversation that followed. A fire blazed in a fireplace, and the entire scene was in living color, with full-surround sound, and in three-dimensional solidity, "indistinguishable from real life." Prior to the ECT, she said, she had never observed or experienced anything remotely resembling the occurrence, and had no conscious memories corresponding to anything or anyone at the party.

Having passed through that puzzling vision, once again she was shooting unimpeded toward the light. Other scenes, in turn, appeared and disappeared. Then there were no more disruptions or intrusions of scenes to distract her gaze or brake her speed; and the threat of being swallowed up and consumed in the light loomed as the imminent, and ultimate, horror.

Drawn, "as if by an inconceivably powerful electromagnet," into that blinding radiance, her terror mounted and matched the light in intensity as she shot down the tunnel with such acceleration, "it felt as if I were being sucked into a black hole in space." And though it was "a thousand times worse than even Dante's most horrifying images of hell," the desire to let go and go into the light was "infinitely compelling, absolutely irresistible."

The struggle had left her totally exhausted, with no energy left to fight against the light; and, having long since passed the point of no return, with courage born of desperation, she at last willed to let go and go into the light, knowing only that death would be release from "unendurable tension, unbearable anxiety."

It was then that she gave herself up to be burned away in the light, to die, to lose her mind, to be hurled into the belching mouth of hell, if that was what was to be. And finally having given up and 
let go to go freely into the light, in a moment, "in the twinkling of an eye," she knew herself to be one with the light itself, and was lost-and found-in a state of "absolute ecstasy."

This time around, oddly enough, it was ECT that played "the sovereign Alchemist" beyond compute, that did, "in a trice, life's leaden metal into gold transmute." Tripped by a most unlikely "philosophers' stone," she had stumbled onto the Golden Fleece, the Holy Grail, the Pearl of Great Price, "All rolled into One."

\section{Postlude}

The next thing she knew, she said, her eyelids opened and she was staring up at the ceiling of her hospital room. Her depression was gone. And, she added with delight, from that moment until the moment four years later when she stepped forward to share her experience, no trace of depression had returned.

It wasn't until later, two years after the seemingly aberrant "tunnel vision," that her puzzlement as to the source of that disconcerting, "dreamlike" cocktail party scene became transformed into realization, and the entire experience was reframed as a small part of a much larger picture.

She had, she said, been invited to a party one evening - in "the real world of objective reality" -and, the moment she entered the host's living room, was astonished to discover everyone and everything exactly as had been observed two years earlier under ECT. The chic woman in the black, satin dress, the man in the houndstooth coat, the furniture and artworks, the fire in the fireplace-it was all there, exactly the same, with every detail precisely in place, save one. The single exception, she emphasized with a curious twinkle in her eye, was that "everything was in reverse-like the negative of a photograph."

Impossible as it may seem, ECT had, in some unexplained, perhaps unexplainable, way triggered a fleeting, yet perfectly clear, glimpse of her future, a glimpse that materialized two years later as a déjà $v u$ with unmistakable historical roots, a pivotal experience she had come, by then, to speak of as "the turning point of my life."

After years of reflection on questions raised in regard to this gifted woman's ECT-induced NDE, at least three possible explanations come to mind in light of personal speculation and related reports in the NDE literature. First, the electrical stimulation itself may, quite lit- 
erally, have been the illuminating factor. Neurosurgical pioneer Wilder Penfield (1955, 1975) elicited reports of out-of-body experiences and life reviews in response to right temporal lobe stimulation of the exposed brains of his subjects.

Second, the anesthesia may have played a role in inducing an idiosyncratically altered state of consciousness, or might actually have brought this individual to the brink of death. Her hyperawareness between anesthetization and electrical stimulation, while she appeared to be unconscious, is intriguing, and may suggest either that she received an insufficient dose of anesthetic (Blacher, 1984), or that her consciousness may already have undergone a radical, "transpersonal" shift into what some near-death observers have described as "Mindat-large" (Grosso, 1985; Ring, 1992). Although her awareness while her body was paralyzed might suggest a separation of mind and body, the fact that she continued to perceive as if she were still lucidly conscious (e.g., seeing the doctor's pupil peering from behind his penlight) suggests that her consciousness and her body were still functioning as a unit at that point, even though her consciousness might seem to have been operating somewhat independently of her anesthetized brain. The literature contains numerous accounts of anesthesia-induced NDEs, including both intentional and serendipitous experiences, some blissful and others terrifying (Ring, 1988, in press; Rogo, 1984).

Third, this woman's conviction that she was about to die may have induced what has been called a "fear-death experience" (Stevenson, Cook, and McClean-Rice, 1989-90), an NDE-like experience brought on by psychological stress and presumed nearness to death without actual life-threatening physiological danger.

It is left to the reader to reflect on the possible significance and implications of this one individual's one encounter with ECT, to wonder about the paradigm-nudging anomaly she experienced in its wake, to realize that "enlightenment" and "lighten up a bit" are so close as to be indistinguishable in the dark, and to remember that one glimpse is worth a thousand reflections.

\section{References}

Blacher, R. S. (1984). Awareness during surgery. Anesthesiology, 61, 1-2.

Grosso, M. (1985). The final choice: Playing the survival game. Walpole, NH: Stillpoint. Haldane, J. B. S. (1975). Possible worlds, and other papers. Salem, NH: Ayer. (Original work published 1927). 
Penfield, W. (1955). The role of the temporal cortex in certain psychical phenomena. Journal of Mental Science, 101, 451-465.

Penfield, W. (1975). The mystery of the mind: A critical study of consciousness and the human brain. Princeton, NJ: Princeton University Press.

Ring, K. (1988). Paradise is paradise: Reflections on psychedelic drugs, mystical experience, and the near-death experience. Journal of Near-Death Studies, 6, 138-148.

Ring, K. (1992). The Omega Project: Near-death experiences, UFO encounters, and mind at large. New York, NY: Morrow.

Ring, $K$. (In press). A note on anesthetically-induced frightening "near-death experiences." Journal of Near-Death Studies.

Rogo, D. S. (1984). Ketamine and the near-death experience. Anabiosis: The Journal of Near-Death Studies, 4, 87-96.

Stevenson, I., Cook, E. W., and McClean-Rice, N. (1989-90). Are persons reporting "near-death experiences" really near death? A study of medical records. Omega, 20, 45-54. 